\title{
Phosphorylation of the ryanodine receptor mediates the cardiac fight or flight response in mice
}

\author{
Jian Shan, ${ }^{1}$ Alexander Kushnir, ${ }^{1}$ Matthew J. Betzenhauser, ${ }^{1}$ \\ Steven Reiken, ${ }^{1}$ Jingdong Li, ${ }^{2}$ Stephan E. Lehnart, ${ }^{1}$ Nicolas Lindegger, ${ }^{3}$ \\ Marco Mongillo, ${ }^{1}$ Peter J. Mohler, ${ }^{2}$ and Andrew R. Marks ${ }^{1,4}$ \\ 1Department of Physiology and Cellular Biophysics, Clyde and Helen Wu Center for Molecular Cardiology, \\ College of Physicians and Surgeons, Columbia University, New York, New York, USA. \\ 2Department of Medicine and Department of Molecular Physiology, Carver College of Medicine, University of lowa, lowa City, Iowa, USA. \\ ${ }^{3}$ Department of Pharmacology and ${ }^{4}$ Department of Medicine, College of Physicians and Surgeons, Columbia University, New York, New York, USA.
}

\begin{abstract}
During the classic "fight-or-flight" stress response, sympathetic nervous system activation leads to catecholamine release, which increases heart rate and contractility, resulting in enhanced cardiac output. Catecholamines bind to $\beta$-adrenergic receptors, causing cAMP generation and activation of PKA, which phosphorylates multiple targets in cardiac muscle, including the cardiac ryanodine receptor/calcium release channel (RyR2) required for muscle contraction. PKA phosphorylation of RyR2 enhances channel activity by sensitizing the channel to cytosolic calcium $\left(\mathrm{Ca}^{2+}\right)$. Here, we found that mice harboring RyR2 channels that cannot be PKA phosphorylated (referred to herein as RyR2-S2808A ${ }^{+/+}$mice) exhibited blunted heart rate and cardiac contractile responses to catecholamines (isoproterenol). The isoproterenol-induced enhancement of ventricular myocyte $\mathrm{Ca}^{2+}$ transients and fractional shortening (contraction) and the spontaneous beating rate of sinoatrial nodal cells were all blunted in RyR2-S2808 $\mathrm{A}^{+/+}$mice. The blunted cardiac response to catecholamines in RyR2-S2808A $\mathrm{A}^{+/+}$mice resulted in impaired exercise capacity. RyR2-S2808A ${ }^{+/+}$mice were protected against chronic catecholaminergic-induced cardiac dysfunction. These studies identify what we believe to be new roles for PKA phosphorylation of RyR2 in both the heart rate and contractile responses to acute catecholaminergic stimulation.
\end{abstract}

\section{Introduction}

During exercise, heart rate (chronotropy) and cardiac contractility (inotropy) increase to meet the metabolic demands of the organs. Stress-induced activation of the sympathetic nervous system (SNS) results in catecholamine release, stimulation of $\beta$-adrenergic receptors ( $\beta$-ARs), generation of cAMP, and activation of cAMP-dependent protein kinase (PKA) in cardiac myocytes. Catecholaminergic stimulation of the heart increases both heart rate and contractility (1). The essential role of $\beta$-ARs in the stress-induced enhancement of cardiac function has been demonstrated using $\beta_{1}$-AR knockout mice that are unable to develop normal responses to stress (2). However, the complexity of the $\beta$-AR signaling cascade has made it difficult to elucidate specific contributions of downstream targets to the physiologic responses to stress.

$\beta$-AR stimulation and downstream activation of PKA enhances calcium $\left(\mathrm{Ca}^{2+}\right)$ signaling in myocytes (3). During excitation-contraction (EC) coupling in the heart, depolarization of the sarcolemmal membrane activates the voltage-gated calcium channel (Cav1.2), causing a small $\mathrm{Ca}^{2+}$ influx into the cell. This in turn triggers the opening of ryanodine receptor/calcium release channel (RyR2) and the release of $\mathrm{Ca}^{2+}$ from the sarcoplasmic reticu-

Authorship note: Jian Shan, Alexander Kushnir, Matthew J. Betzenhauser, and Steven Reiken contributed equally to this work.

Conflict of interest: Andrew R. Marks is a consultant for a start-up company, ARMGO Pharma Inc., that is targeting RyR2 to prevent heart failure and sudden cardiac death.

Citation for this article: J Clin Invest. 2010;120(12):4388-4398. doi:10.1172/JCI32726. lum (SR) (4-6). $\mathrm{Ca}^{2+}$ released into the cytosol binds to troponin C, enabling sarcomere shortening and contraction. Relaxation occurs when the $\mathrm{Ca}^{2+}$ is pumped back into the $\mathrm{SR}$ by the $\mathrm{SR} \mathrm{Ca}^{2+}$ ATPase (SERCA2a) and removed from the cell via the sodium/calcium exchanger (NCX) and the plasmalemmal $\mathrm{Ca}^{2+}$ ATPase (3).

In response to SNS activation, PKA phosphorylates multiple $\mathrm{Ca}^{2+}$-handling proteins, including $\mathrm{Ca}_{v} 1.2$, phospholamban (PLN), and RyR2. Phosphorylation of $\mathrm{Ca}_{\mathrm{v}} 1.2$ increases the open probability (Po) of the channel (7), which enhances inward $\mathrm{Ca}^{2+}$ current $\left(I_{C a, L}\right)$ during depolarization. Phosphorylation of PLN at Ser16 reduces its basal inhibition of SERCA2a, leading to increased SERCA2a activity and increased SR $\mathrm{Ca}^{2+}$ uptake (8). Phosphorylation of RyR2 at Ser2808 enhances the Po of the channel by enhancing its sensitivity to cytosolic $\left[\mathrm{Ca}^{2+}\right]$ in planar lipid bilayers $(9,10)$. While it is well established that increasing $\mathrm{I}_{\mathrm{Ca}, \mathrm{L}}$ and $\mathrm{SR}$ $\mathrm{Ca}^{2+}$ load enhance SR Ca ${ }^{2+}$ release (11), it is controversial as to whether increasing RyR2 Po has similar effects $(3,11-20)$. In this study, we have used mice engineered with RyR2 that cannot be PKA phosphorylated (21) to directly address the role of PKA phosphorylation of RyR2 in regulating cardiac contractility.

Heart rate is dependent on the periodic diastolic depolarization (DD) of pacemaker cells in the sinoatrial (SA) node. The automaticity of DD has been linked to hyperpolarization-activated cyclic nucleotide gated channels (HCN4), which produce an inward "funny current" $\left(\mathrm{I}_{\mathrm{f}}\right)$ in response to hyperpolarizing membrane potentials $(22,23)$. Activation of either the SNS or parasympathetic nervous system modulates HCN4/If via cAMP (24) or acetylcholine (25), respectively. More recently, small rhythmic SR 

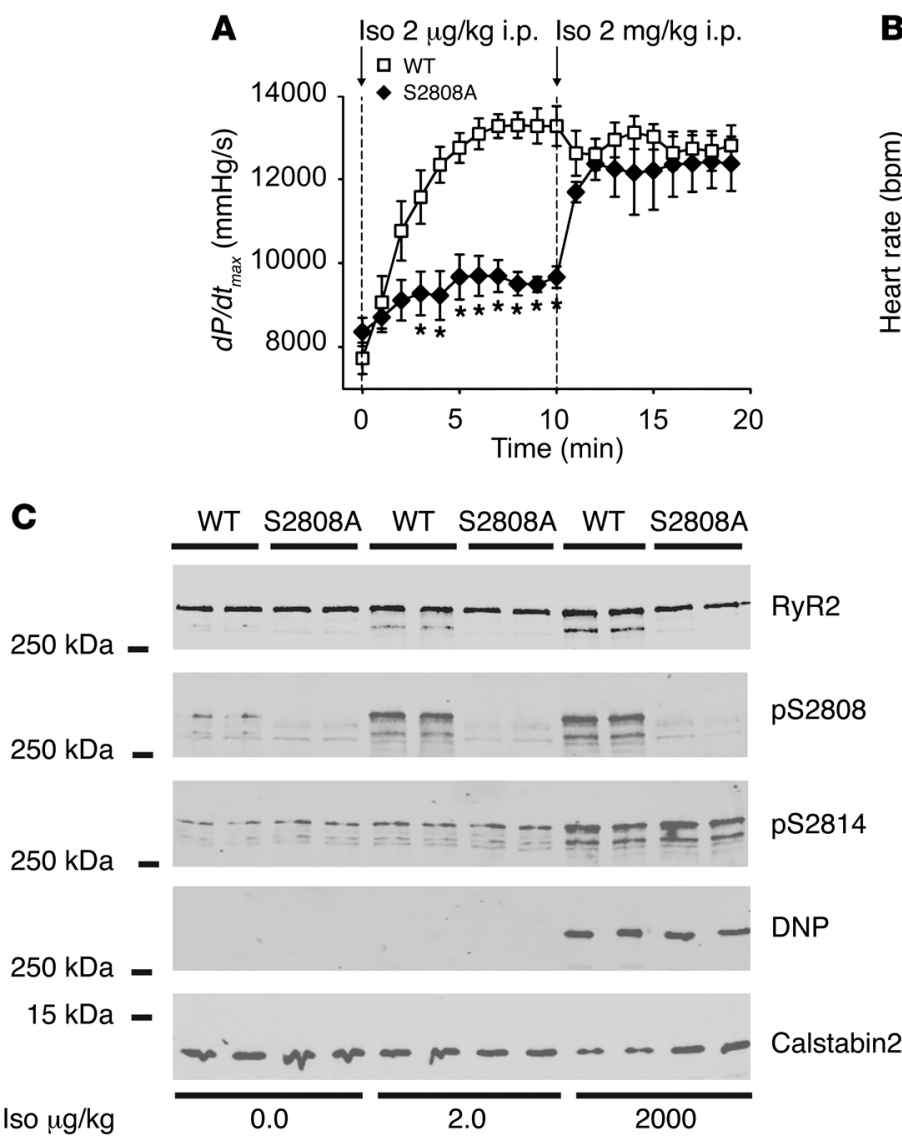

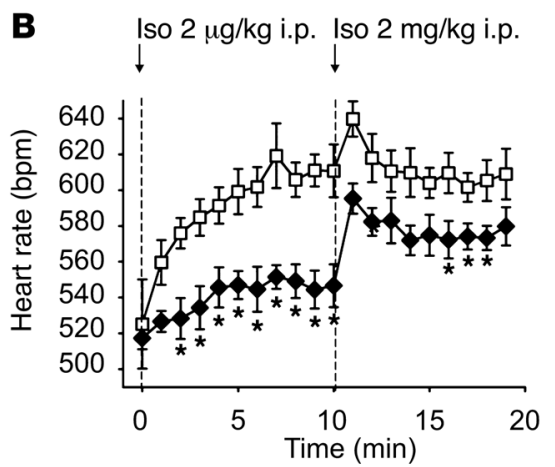

D

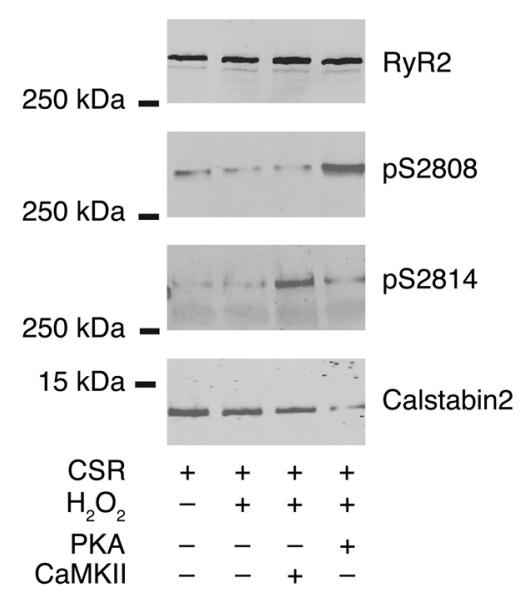

Figure 1

PKA phosphorylation of RyR2 mediates the chronotropic and inotropic response to $\beta$-adrenergic activation. Cardiac contractility and heart rate were measured in vivo using left ventricular catheterization in response to low-dose (2 $\mu \mathrm{g} / \mathrm{kg}$ i.p.) and high-dose (2 mg/kg i.p.) Iso. (A) Contractility reported as $d P / d t_{\max }$. (B) Heart rate in bpm. Dashed lines indicate the points at which Iso was administered i.p. (WT, $n=5$; RyR2-S2808A ${ }^{+/+}$, $n=6$; ${ }^{*} P<0.05$, versus WT). (C) Representative immunoblot analyses of RyR2 immunoprecipitates (from $100 \mu \mathrm{g}$ of cardiac lysates), using phosphoepitope-specific antibodies that detect PKA-phosphorylated RyR2-Ser2808 (pS2808), CaMKII-phosphorylated RyR2-Ser2814 (pS2814), oxidation of RyR2 (DNP), and calstabin2 associated with the channel. (D) Representative immunoblot of CSR treated with hydrogen peroxide $\left(\mathrm{H}_{2} \mathrm{O}_{2}\right)$ plus either PKA or CaMKII and levels of calstabin2 associated with the channel. S2808A, RyR2-S2808A ${ }^{+/+}$.

$\mathrm{Ca}^{2+}$ release events during DD, referred to as localized $\mathrm{Ca}^{2+}$ release (LCR), have been described. These events activate the plasmalemmal NCX, resulting in transient inward current, which contributes to depolarization $(26,27)$. While some studies suggest that SNS-mediated activation of $\beta$-ARs causes PKA phosphorylation of RyR2 in the SA node, which enhances the quantity and synchronization of LCR during DD (28), the role of PKA phosphorylation of RyR2 in the chronotropic response to SNS activation has not been determined.

We now show that RyR2-S2808A ${ }^{+/+}$mice, which lack the PKA phosphorylation site on RyR2, have blunted inotropic and chronotropic responses to catecholaminergic activation. This is associated with blunted systolic $\mathrm{Ca}^{2+}$ transients and spontaneous beating rates in response to isoproterenol (Iso) in isolated cardiomyocytes and SA nodal cells (SANCs), respectively. Furthermore, these animals have reduced exercise capacity compared with that of WT mice. Chronic pharmacologic activation of $\beta$-ARs, as occurs in patients with heart failure $(\mathrm{HF})$, caused cardiac dysfunction in WT but not RyR2-S2808A $\mathrm{A}^{+/+}$mice. These results demonstrate that PKA phosphorylation of a single residue in RyR2 (Ser2808) mediates a physiological response to acute stress that includes increased inotropic and chronotropic responses and that chronic, pathologic stimulation of this stress pathway contributes to progression of cardiac dysfunction.

\section{Results}

$P K A$ phosphorylation of RyR2 is required for normal cardiac responses to $\beta$-adrenergic activation. Left ventricular contractility and heart rate were continuously recorded in anesthetized WT and RyR2$\mathrm{S} 2808 \mathrm{~A}^{+/+}$mice treated with the $\beta$-agonist Iso $(2 \mu \mathrm{g} / \mathrm{kg}$ i.p. for 10 minutes, followed by $2 \mathrm{mg} / \mathrm{kg}$ i.p.). Another group had reported that an independently generated RyR2-S2808 $\mathrm{A}^{+/+}$mouse exhibited a normal contractile response to Iso ( $2 \mathrm{mg} / \mathrm{kg}$ i.p.) (12). In the present study, the RyR2-S2808A $\mathrm{A}^{+/+}$mice exhibited a significantly blunted contractile response (WT, 13,268 $\pm 418 \mathrm{mmHg} / \mathrm{s}, n=5$; RyR2-S2808A $\left.{ }^{+/+}, 9,491 \pm 178 \mathrm{mmHg} / \mathrm{s} n=6 ; P<0.001\right)$ and heart rate response (WT, $611 \pm 15 \mathrm{bpm}, n=5$; RyR2-S2808A $\mathrm{A}^{+/+}, 547 \pm 12$ bpm, $n=6 ; P<0.01$ ) to the lower Iso dose but similar responses to those of WT mice at the 1,000-fold higher Iso dose (Figure 1, A and B). Both doses of Iso induced PKA phosphorylation of WT RyR2 at Ser2808; however, only the higher dose resulted in depletion of calstabin2 from the channel (Figure 1C and Supple- 
A

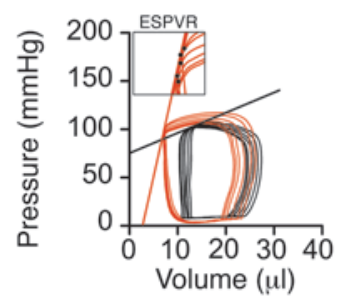

E Baseline

- db-cAMP

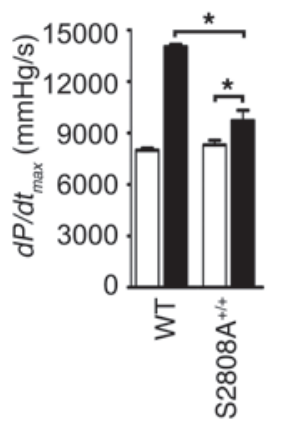

B

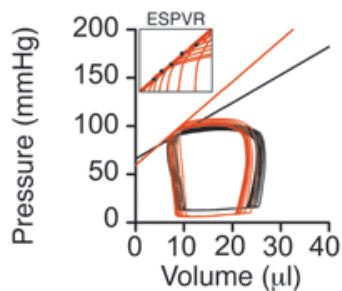

F

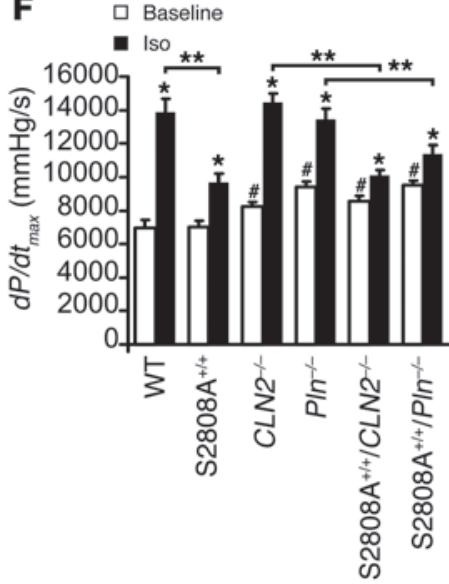

C $52808 \mathrm{~A}^{+/ 4+}$

Bay K 8644

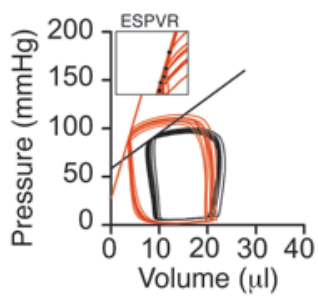

G $\quad$ wT

- S2808A

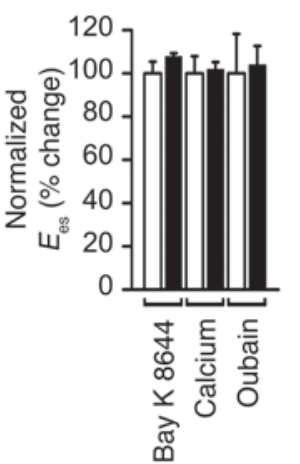

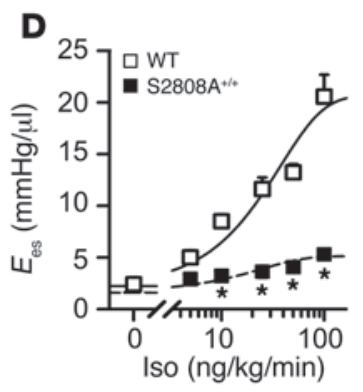

H a wT

- S2808A

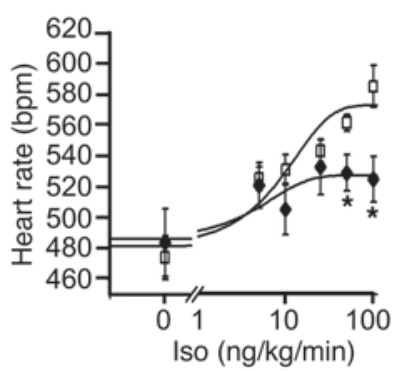

\section{Figure 2}

Blunted cardiac response to acute $\beta$-adrenergic stimulation in RyR2-S2808A $\mathrm{A}^{+/+}$mice. (A-C) Pressure-volume loops before (black) and during (red) Iso (100 ng/kg/min i.v.) infusion. (A) The steeper and left-shifted $E_{\text {es }}$ line indicates increased contractility as evidenced in WT, which is blunted in (B) RyR2-S2808A ${ }^{+/+}$mice. (C) Treatment with Bay K 8644 (100 $\mu \mathrm{g} / \mathrm{kg}$ i.p.) restored the inotropic response in RyR2-S2808A ${ }^{+/+}$mice. Insets show representative examples of end-systolic pressure-volume relationships (ESPVRs) during $\beta$-adrenergic stimulation; $E_{\mathrm{es}}$ is determined by the slope of the automated end-systolic pressure-volume relationship regression analysis through a series of end-systolic points (black dots). (D) $E_{\text {es }}$ response to gradually increasing Iso $(0-100 \mathrm{ng} / \mathrm{kg} / \mathrm{min})$ and sigmoid regression analysis $\left(n=10\right.$ for each genotype; ${ }^{*} P<0.05$ each versus WT). (E) $d P / d t_{\max }$ of WT and RyR2-S2808A ${ }^{+/+}$mice prior to and after db-cAMP infusion $\left({ }^{*} P<0.05\right)$. (F) $d P / d t_{\max }$ prior to and after treatment with Iso (100 ng/kg/min i.v.), according to genotype as indicated (calstabin2, referred to herein as CLN2 ${ }^{-1-}$; phospholamban, $P / n^{-1-}$; and crossed mouse strains as indicated) $\left({ }^{\star} P<0.05\right.$ versus baseline; ${ }^{\#} P<0.05$ versus WT baseline; $\left.{ }^{* \star} P<0.05\right)$. (G) $E_{\text {es }}$ change normalized to WT after treatment with inotropic agonists Bay K 8644 (100 $\mu \mathrm{g} / \mathrm{kg}$ i.p.), $\mathrm{Ca}^{2+}(30 \mathrm{mg} / \mathrm{kg} / \mathrm{min}$ i.v.), or ouabain $(0.1 \mathrm{mg} / \mathrm{kg} / \mathrm{min}$ i.v.) $(P=\mathrm{NS}$ versus WT; $n=5)$. (H) Heart rates in response to gradually increasing Iso concentrations $(0-100 \mathrm{ng} / \mathrm{kg} / \mathrm{min})$ and sigmoid regression analysis from $\mathbf{D}(n=10$ for each genotype; $\left.{ }^{*} P<0.05\right)$.

mental Figure 1, A and B; supplemental material available online with this article; doi:10.1172/JCI32726DS1). RyR2 from the RyR2-S2808A ${ }^{+/+}$mice exhibited no phosphorylation signal when probed with the phospho-specific Ser2808 antibody and were not depleted of calstabin2 (FKBP12.6) at either dose of Iso (Figure 1C and Supplemental Figure 1, A and B). Interestingly, the higher dose of Iso induced CaMKII phosphorylation of RyR2 at Ser2814 $(10,29)$ in both WT and RyR2-S2808A $\mathrm{A}^{+/+}$mice (Figure $1 \mathrm{C}$ and Supplemental Figure 1C). The higher Iso dose also caused oxidization of RyR2 in both WT and RyR2-S2808A ${ }^{+/+}$mice (Figure 1C and Supplemental Figure 1D).

To further investigate the effects of oxidation of RyR2, we incubated cardiac SR (CSR) with hydrogen peroxide $\left(\mathrm{H}_{2} \mathrm{O}_{2}\right)$ plus either PKA or CaMKII. Oxidation alone and oxidation plus CaMKII had little if any effect on the binding of calstabin2 to RyR2 (Figure 1D). However, the combination of PKA phosphorylation of RyR2 at Ser2808 and oxidation of the channel resulted in nearly complete depletion of calstabin2 from the RyR2 channel complex (Figure 1D).

Taken together these data show that there is a significant blunting of both the inotropic and chronotropic responses to
Iso in the RyR2-S2808A $\mathrm{A}^{+/+}$mice, consistent with PKA phosphorylation of RyR2 playing a key role in both of these important physiological responses. These blunted inotropic and chronotropic responses can be obscured when the mice are treated with a 1,000-fold higher dose of Iso, and this effect is likely due to CaMKII phosphorylation, which has been previously demonstrated to enhance contractility (29), even in the absence of PKA phosphorylation of the channel.

We found no significant differences in peak $\mathrm{I}_{\mathrm{Ca}, \mathrm{L}}$ between $\mathrm{WT}$ and RyR2-S2808A $\mathrm{A}^{+/+}$myocytes, either in the absence or presence of Iso, measured under whole-cell voltage clamp at $0 \mathrm{mV}$ (control: WT, $-6.9 \pm 0.8 \mathrm{pA} / \mathrm{pF}, n=10$; RyR2-S2808A ${ }^{+/+},-9.2 \pm 1.3 \mathrm{pA} / \mathrm{pF}, n=5$; Iso: WT, $-11.4 \pm 1.4 \mathrm{pA} / \mathrm{pF}, n=10$; RyR2-S2808A ${ }^{+/+},-13.0 \pm 0.9 \mathrm{pA} / \mathrm{pF}$, $n=5 ; P=$ NS for Iso-treated WT vs. RyR2-S2808A ${ }^{+/+}$myocytes). Similarly, Iso enhanced the activity of the SERCA2a in cardiac microsomes isolated from RyR2-S2808A $\mathrm{A}^{+/+}$or WT mice to the same extent (Supplemental Figure 2). Moreover, $\beta$-AR densities were the same in RyR2-S2808A $\mathrm{A}^{+/+}$and WT mice (Supplemental Table 1). These data demonstrate that PKA-mediated activation of $\mathrm{Ca}_{V} 1.2$ and SERCA2a is intact in RyR2-S2808 $\mathrm{A}^{+/+}$hearts. 

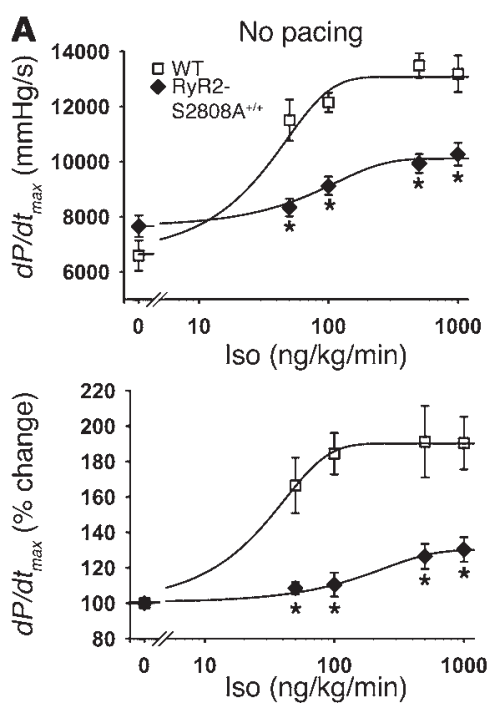
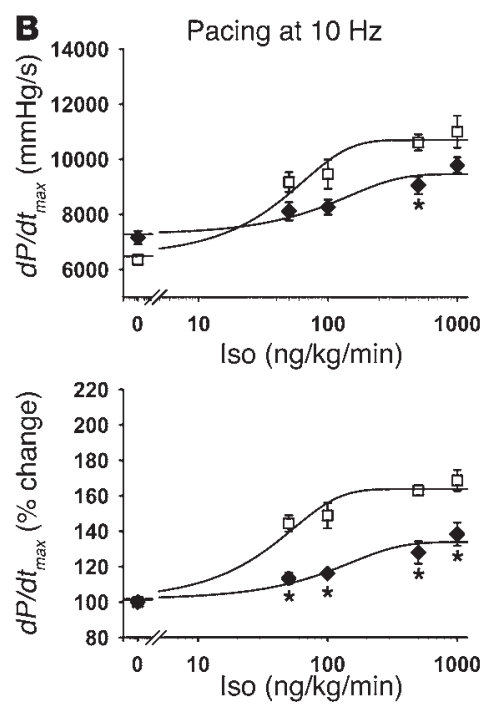

\section{Figure 3}

Blunted inotropic responses to Iso in RyR2-S2808 $\mathrm{A}^{+/+}$ mice in the absence and presence of $10 \mathrm{~Hz}$ pacing. Iso dose-dependent enhancement of cardiac contractility in WT versus RyR2-S2808 $\mathrm{A}^{+/+}$mice, with or without heart rate control (via right ventricular pacing). Cardiac contractility measured in vivo by left ventricular catheterization in WT $(n=6)$ versus RyR2-S2808A $\mathrm{A}^{+/+}$mice $(n=7)$. (A) Cardiac contractility measured without RV pacing. The top panel shows $d P / d t_{\max }$, and bottom panel shows the percentage change in $d P / d t_{\max }$. (B) Cardiac contractility measured with RV pacing at $10 \mathrm{~Hz}$ (heart rate $=600 \mathrm{bpm}$ ). ${ }^{*} P<0.05$ versus WT.
To further explore the role of PKA phosphorylation of RyR2 in the inotropic and chronotropic response to adrenergic stimulation, we used intracardiac catheterization to monitor left ventricular pressure-volume relationships in the absence and presence of inferior vena cava constriction. This approach yields the end-systolic elastance $\left(E_{\mathrm{es}}\right)$, which is a measure of contractility that is independent of changes in preload. Baseline $E_{\text {es }}$ was equal in WT and RyR2-S2808 $\mathrm{A}^{+/+}$mice (WT, $2.4 \pm 0.1 \mathrm{mmHg} / \mu \mathrm{l}, n=10$; RyR2-S2808A $\left.{ }^{+/+}, 2.3 \pm 0.1 \mathrm{mmHg} / \mu \mathrm{l}, n=10 ; P=\mathrm{NS}\right)$. Iso infusion $(100 \mathrm{ng} / \mathrm{kg} / \mathrm{min}$ i.v. $)$ caused WT $E_{\text {es }}$ to increase to $19.2 \pm 1.2 \mathrm{mmHg} / \mu \mathrm{l}$ compared with $5.0 \pm 0.6 \mathrm{mmHg} / \mu \mathrm{l}$ in the RyR2-S2808 $\mathrm{A}^{+/+}$mice $(P<0.001$; Figure 2, A, B, and D). Maximal contractility, calculated as the maximal rate of change in pressure over time $\left(d P / d t_{\text {max }}\right)$, after Iso infusion was blunted in the RyR2-S2808A ${ }^{+/+}$mice (WT, $14,365 \pm 594 \mathrm{mmHg} / \mathrm{s}, n=16 ; \mathrm{RyR} 2-\mathrm{S} 2808 \mathrm{~A}^{+/+}, 9,814 \pm 402 \mathrm{mmHg} / \mathrm{s}$, $n=17 ; P<0.001$; Figure 2F and Supplemental Table 2). RyR2$\mathrm{S} 2808 \mathrm{~A}^{+/+}$mice also exhibited a blunted increase in maximal heart rate after Iso infusion (WT, $575 \pm 11 \mathrm{bpm}, n=16$; RyR2-S2808A $\mathrm{A}^{+/}$, $520 \pm 9 \mathrm{bpm}, n=17 ; P<0.001$; Figure $2 \mathrm{H}$ and Supplemental Table 2). The blunted inotropic and chronotropic responses to Iso in the RyR2-S2808A ${ }^{+/+}$mice were also observed in response to nonhydrolyzable dibutyryl-cAMP (db-cAMP) $(10 \mathrm{mg} / \mathrm{kg}$ i.v.), which directly activated PKA (Figure 2E and Supplemental Table 3). WT and RyR2-S2808A ${ }^{+/+}$mice had similar responses to inotropic agents that increase contractility, independently of the $\beta$-AR pathway, including Bay K 8644 (L-type calcium channel agonist) (Figure 2, $\mathrm{C}$ and $\mathrm{G}$ ), high extracellular calcium (Figure $2 \mathrm{G}$ ), and ouabain (Figure 2G), ruling out the possibility that the RyR2-S2808 $\mathrm{A}^{+/+}$ hearts cannot respond to catecholamines for a reason unrelated to the inability of PKA to phosphorylate RyR2.

Since PKA-dependent phosphorylation of PLN increases contractility by enhancing SERCA2a activity and SR $\mathrm{Ca}^{2+}$ uptake (3), we used PLN-deficient mice to examine the relative contribution of PKA phosphorylation of RyR2 and PLN in the "fight-orflight" response. Pln-knockout mice exhibited increased baseline contractility and a normal maximal increase in contractility in response to Iso infusion (Figure $2 \mathrm{~F}$ ), as previously reported (30). A cross between Pln-deficient mice and RyR2-S2808A ${ }^{+/+}$mice yielded mice with baseline contractility similar to that of the Plnknockout mice, but with a blunted response to Iso similar to that of the RyR2-S2808A ${ }^{+/+}$mice (Figure 2F). These data demonstrate that PKA phosphorylation of RyR2 contributes to the inotropic response to $\beta$-adrenergic activation, even in the setting of genetically enhanced SERCA2a function.

Cardiac function of calstabin2-deficient mice was enhanced at baseline (Figure 2F), in concordance with the observation that cardiomyocytes isolated from these mice have enhanced SR $\mathrm{Ca}^{2+}$ release (31). A cross between the calstabin2-deficient mice and RyR2-

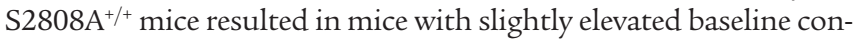
tractility and a blunted contractile response to Iso (Figure $2 \mathrm{~F}$ ).

Due to the well-established relationship between heart rate and contractility (32), we investigated whether the blunted inotropic response to Iso in the RyR2-S2808 $\mathrm{A}^{+/+}$mice in vivo could be explained by the diminished chronotropic response. Using intracardiac pacing, WT and RyR2-S2808A ${ }^{+/+}$mice were pre-paced at $10 \mathrm{~Hz}(600 \mathrm{bpm})$ prior to and during Iso infusion (Figure 3B). The paced RyR2-S2808 $\mathrm{A}^{+/+}$mice exhibited reduced but significant blunting of the inotropic response to Iso (WT, 10,614 $\pm 290 \mathrm{mmHg} / \mathrm{s} d P / d t_{\max }, n=6$; RyR2-S2808A ${ }^{+/+}$, $9,057 \pm 311 \mathrm{mmHg} / \mathrm{s} d P / d t_{\max }, n=7 ; P<0.05$ ) (Figure 3B), demonstrating that PKA phosphorylation of RyR2 independently enhances both heart rate and contractility.

We next performed ex vivo assessments of cardiac contractility using Langendorff-perfused hearts to confirm that the blunted inotropic response to Iso in the RyR2-S2808 $\mathrm{A}^{+/+}$mice was specifically due to defective enhancement of myocardial contractility, independent of systemic vascular and neurohormonal regulation. Exclusion criteria for this study were designed to minimize differences in maximal heart rates between WT and RyR2-S2808 $\mathrm{A}^{+/+}$ hearts (Supplemental Table 4). This approach enabled the examination of contractility, while minimizing heart rate differences. WT and RyR2-S2808 $\mathrm{A}^{+/+}$hearts had baseline developed pressures of $59 \pm 3 \mathrm{mmHg}$ and $56 \pm 2 \mathrm{mmHg}$, respectively, which, when hearts were treated with $100 \mathrm{nM}$ Iso, increased to $185 \pm 10 \mathrm{mmHg}$ in WT and $145 \pm 7$ mmHg in RyR2-S2808A ${ }^{+/+}$hearts (WT, $n=7$; RyR2-S2808A ${ }^{+/+}$, $n=9 ; P<0.01)$. Contractility, calculated as $d P / d t_{\max }$, was significantly higher in the WT hearts, compared with that in the RyR2-S2808 $\mathrm{A}^{+/+}$ hearts (WT, $8,517 \pm 272 \mathrm{mmHg} / \mathrm{s} d P / d t_{\text {max }}, n=7$; RyR2-S2808A ${ }^{+/+}$, $\left.6,729 \pm 440 \mathrm{mmHg} / \mathrm{s} d P / d t_{\max }, n=9 ; P<0.01\right)$, after Iso $(100 \mathrm{nM})$ treatment (Figure 4). 
A

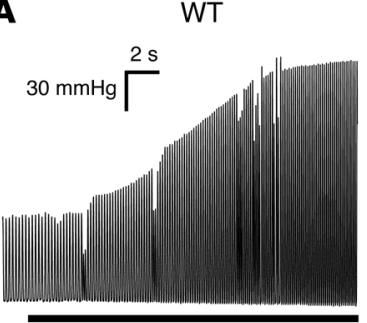

$100 \mathrm{nM}$ Iso

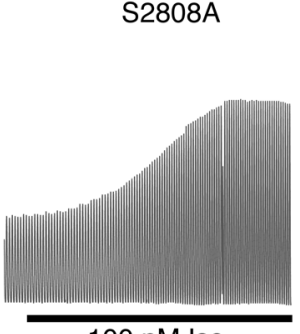

$100 \mathrm{nM}$ Iso

\section{B}

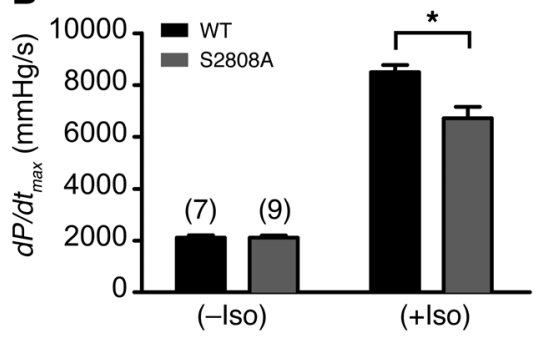

Figure 4

Blunted Iso-induced contractility in RyR2-S2808A ${ }^{+/+}$ex vivo hearts. Contractility measurements of WT $(n=7)$ and RyR2-S2808A ${ }^{+/+}(n=9)$ isolated hearts in the absence and presence of $100 \mathrm{nM}$ Iso. (A) Representative traces of left ventricular pressure before and during Iso infusion, demonstrating blunted developed pressure response to Iso in the RyR2-S2808A $\mathrm{A}^{+/+}$hearts (B) Quantitative summary of $d P / d t_{\max }\left({ }^{\star} P<0.01\right.$ ).

Ventricular cardiomyocytes and SANCs isolated from the RyR2-S2808A $A^{+/+}$ mice have blunted responses to Iso. Electrically evoked $\mathrm{Ca}^{2+}$ transient amplitudes were measured in isolated ventricular cardiomyocytes loaded with Fura- 2 to explore the cellular mechanisms underlying the blunted inotropic response to $\beta$-adrenergic activation in the RyR2-S2808A ${ }^{+/+}$mice. The baseline $\mathrm{Ca}^{2+}$ transient amplitude of cells paced at $3 \mathrm{~Hz}$ was similar in WT and RyR2-S2808 $\mathrm{A}^{+/+}$myocytes but increased in the presence of $100 \mathrm{nM}$ Iso by $50.1 \% \pm 5.4 \%$ in WT myocytes compared with $31.3 \% \pm 4.1 \%$ RyR2-S2808A ${ }^{+/+}$myocytes (WT, $n=16 ; \mathrm{RyR} 2-\mathrm{S} 2808 \mathrm{~A}^{+/+}, n=10 ; P<0.05$ for WT vs. RyR2-S2808A $\mathrm{A}^{+/+}$ percent increase) (Figure 5, A and B). Cell shortening was also blunted in RyR2-S2808A $\mathrm{A}^{+/+}$cardiomyocytes treated with $100 \mathrm{nM}$ Iso compared with that of WT cardiomyocytes (change in cardiomyocyte length: WT, $27 \pm 2 \mu \mathrm{m}, n=10$; RyR2-S2808A ${ }^{+/+}, 21 \pm 1 \mu \mathrm{m}, n=11$; $P<0.05$ ), measured using video edge detection (Figure 5, C and D).

The blunted chronotropic response of the RyR2-S2808A $\mathrm{A}^{+/+}$ hearts to Iso was further investigated by measuring the rate of spontaneous action potential (SAP) generation in SANCs isolated
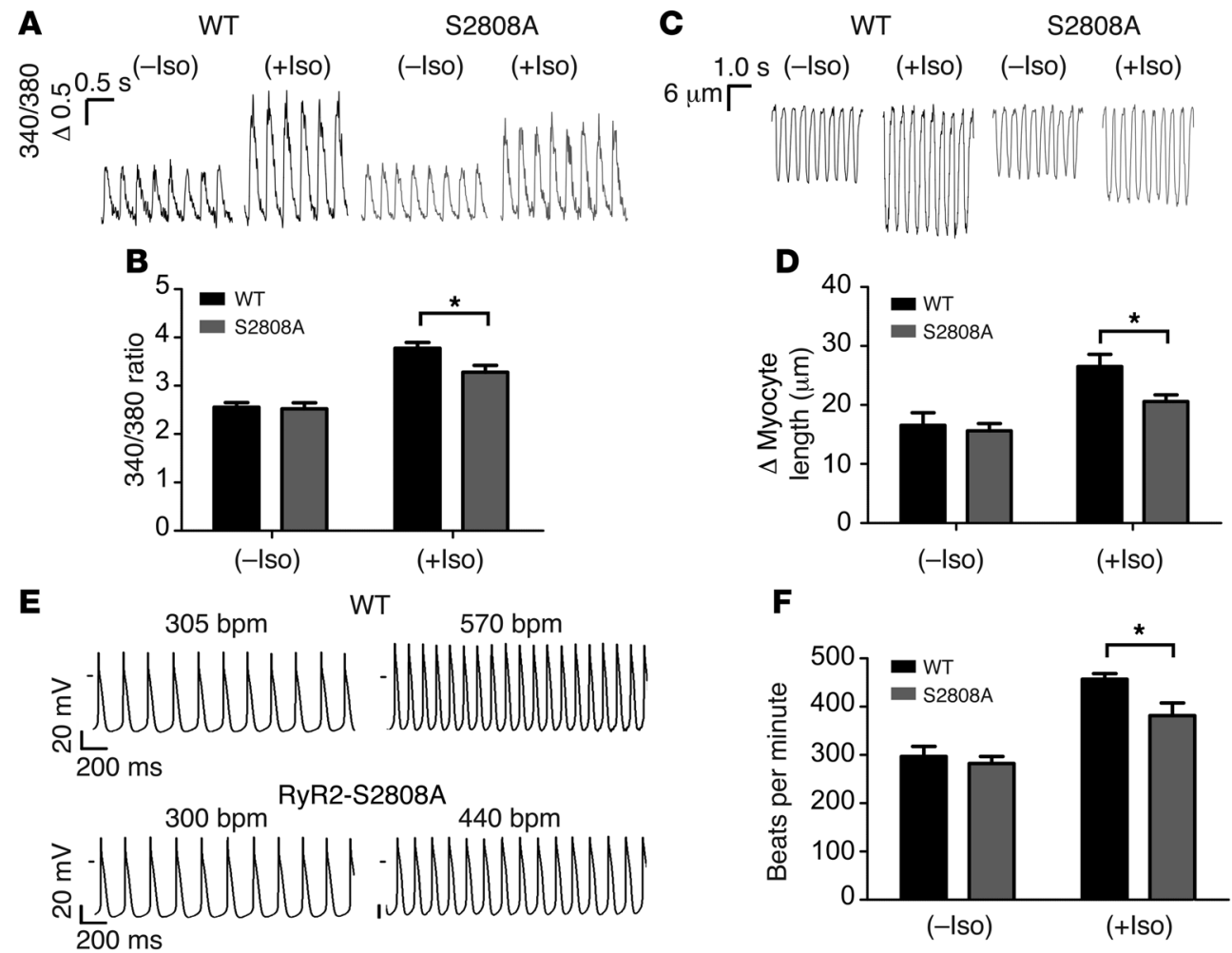

Figure 5

Blunted responses to Iso in RyR2-S2808A+/+ ventricular myocytes and SANCs. (A) Representative $\mathrm{Ca}^{2+}$ transients and (C) fractional shortening traces from WT and RyR2-S2808 $\mathrm{A}^{+/+}$ventricular myocytes loaded with Fura-2 paced at $3 \mathrm{~Hz}$ in the absence and presence of $100 \mathrm{nM}$ Iso. The label " $\Delta 0.5$ " refers to a 0.5 change in the Fura-2 (340:380) ratio. (B) Summary of Ca ${ }^{2+}$ transient and (D) fractional shortening data, demonstrating that the RyR2-S2808A $\mathrm{A}^{+/+}$myocytes have blunted increases in $\mathrm{Ca}^{2+}$ transient and fractional shortening amplitude in response to Iso ( ${ }^{*} P<0.05$ ). (E) Representative SAPs generated from WT and RyR2-S2808A+/+ SANCs in the absence (left) and presence of $50 \mathrm{nM}$ Iso (right). (F) Bar graph summarizing the rate of SAP generation in WT $(n=9)$ versus RyR2-S2808A ${ }^{+/+}$SANCs $\left(n=8 ;{ }^{*} P<0.05\right)$. 
A

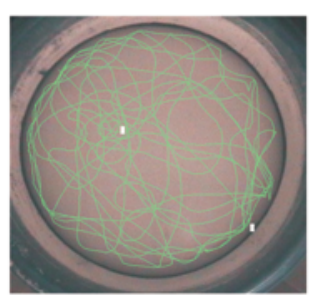

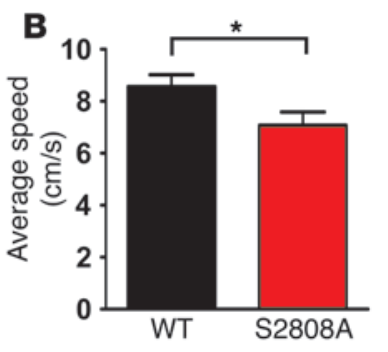

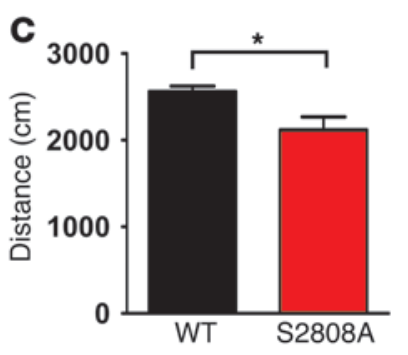

Figure 6

RyR2-S2808A $\mathrm{A}^{+/+}$mice exhibit reduced exercise capacity. (A) Representative tracing of the computer generated swimming pattern of a mouse placed in a large water bath (diameter $122 \mathrm{~cm}$ ) for 5 minutes. White squares represent starting and ending positions. (B and $\mathbf{C}$ ) Graphical representation of the average (B) swimming velocity and $(\mathbf{C})$ distance of WT and RyR2-S2808A $\mathrm{A}^{+/+}$mice over the course of 5 minutes (WT, $n=17$; RyR2-S2808A ${ }^{+/+}, n=18 ;{ }^{*} P<0.05$ ).

from WT and RyR2-S2808A ${ }^{+/+}$hearts. The identity of the SANCs was confirmed by staining the cells with anti-HCN4 antibodies (Supplemental Figure 3). Both WT and RyR2-S2808A+/+ SANCs had similar baseline SAP frequency; however, in the presence of $50 \mathrm{nM}$ Iso, there was a greater rate of spontaneous activity in the WT SANCs ( $457 \pm 12 \mathrm{bpm}, n=9$ cells) compared with that in the RyR2-S2808A ${ }^{+/+}$cells $(381 \pm 26$ bpm, $n=8$ cells; $P<0.05)$ (Figure 5, $\mathrm{E}$ and $\mathrm{F})$. These data indicate that the blunted heart rate response to Iso observed in the RyR2-S2808 $\mathrm{A}^{+/+}$mice in vivo can be explained, at least in part, by the lack of Iso-induced PKA phosphorylation of RyR2 in SANCs.

Reduced exercise capacity in mice lacking the RyR2 PKA phosphorylation site. Taken together, our data suggest a role for PKA phosphorylation of RyR2 in the upregulation of cardiac function in response to acute $\beta$-adrenergic activation. To determine whether the impaired inotropic and chronotropic responses observed in the RyR2-S2808 $\mathrm{A}^{+/+}$mice result in reduced exercise capacity, we measured the swimming speed and distance of untrained WT and RyR2-S2808A ${ }^{+/+}$mice, placed individually in a large water bath (diameter $122 \mathrm{~cm}$ ) at $21^{\circ} \mathrm{C} \pm 1^{\circ} \mathrm{C}$ for 5 minutes (Figure 6A). The RyR2-S2808A ${ }^{+/+}$mice swam significantly slower and for a shorter distance than WT mice (WT, $n=17$; RyR2-S2808A ${ }^{+/+}, n=18$; $P<0.05$ ) (Figure 6, B and C).

The RyR2-S2808 $A^{+/+}$mice are protected from the deleterious effects of chronic $\beta$-adrenergic activation. We have previously demonstrated that the characteristic hyperadrenergic state of HF (33) induces chronic PKA phosphorylation of RyR2 and remodeling of the channel complex (34). Furthermore, $\beta$-blocker treatment, which improves outcomes in HF (35), reduces phosphorylation of RyR2 at Ser2808 and prevents remodeling of the channel complex (34). Consequently, we sought to determine whether the RyR2S2808 $\mathrm{A}^{+/+}$mice were protected from the detrimental effects of chronic $\beta$-adrenergic activation $(36,37)$. Mice were treated with continuous Iso via an osmotic minipump for 8 weeks $(30 \mathrm{mg} / \mathrm{kg} / \mathrm{d})$ to simulate chronic activation of the SNS. In WT mice, echocardiography revealed an initial enhancement of cardiac function, followed by a progressive decline in left ventricular ejection fraction (EF) (Figure 7A), and increased left-ventricular end-systolic dimension (LVESD) (Figure 7B). In contrast, Iso treatment had no significant acute or chronic effect on cardiac function in the RyR2-S2808A ${ }^{+/+}$mice (Figure 7A). Left ventricular mass increased in both WT and RyR2-S2808A $\mathrm{A}^{+/+}$mice; however, the increase in the RyR2-S2808A ${ }^{+/+}$mice was significantly smaller than that in the RyR2-S2808 $\mathrm{A}^{+/+}$mice. Furthermore, the oxidation level of RyR2 was significantly reduced in the RyR2-S2808A $\mathrm{A}^{+/+}$mice at 8 weeks of Iso treatment compared with that in WT mice at 8 weeks. There were no significant differences in PKA phosphorylation of PLN between the WT and RyR2-S2808A ${ }^{+/+}$mice at 0,4 , and 8 weeks of chronic Iso treatment (Figure 7C). We next sought to determine the functional consequences of the protection against calstabin2 depletion from the RyR2 complex observed in the RyR2-S2808A ${ }^{+/+}$mice at the singlechannel level. In contrast to the PKA hyperphosphorylated and oxidized channels from chronically Iso-treated WT mice, which exhibited increased Po at low activating $\mathrm{Ca}^{2+}$ concentrations (consistent with "leaky" channels) (Figure $7 \mathrm{H}$ ), the channels from the Iso-treated RyR2-S2808A $\mathrm{A}^{+/+}$mice had significantly lower Po (nonleaky channels) (Figure 7, I and J).

\section{Discussion}

It has long been recognized that $\beta$-adrenergic stimulation potently enhances heart rate, contractility, and cardiac output. However, positive chronotropy and inotropy in the heart have primarily been attributed to enhancement of $\mathrm{I}_{\mathrm{f}}, \mathrm{Ca}_{\mathrm{v}} 1.2$, and SERCA2a activities $(8,23,38,39)$. The complex interdependent nature of adrenergic pathways and $\mathrm{Ca}^{2+}$ signaling in the heart and the multitude of substrates for PKA phosphorylation have precluded the identification of the specific contribution of PKA phosphorylation of RyR2 in this fundamental stress response. The availability of a mutant murine model harboring a RyR2 channel that cannot be PKA phosphorylated provides a suitable in vivo model that can be used to directly assess the role of this $\mathrm{SR} \mathrm{Ca}^{2+}$ release channel in catecholamine-induced enhancement of heart rate and contractility.

We and others have previously reported that PKA phosphorylation of RyR2 enhances channel activity and/or RyR2-mediated SR $\mathrm{Ca}^{2+}$ release $(9,10,16-18,40,41)$. However, these studies were performed on isolated cardiomyocytes (16-18) or on channels reconstituted in planar lipid bilayer $(9,10,40,41)$, making it difficult to assess the in vivo physiological relevance. In the present study, we have observed that RyR2-S2808A ${ }^{+/+}$mice, which lack the major PKA phosphorylation site on RyR2 (21), have a blunted chronotropic and inotropic response to $\beta$-adrenergic activation in vivo and at the isolated organ and cardiomyocyte levels. Furthermore, these mice exhibited impaired exercise capacity, suggesting that PKA phosphorylation of RyR2 in the heart contributes to the cardiac response to acute catecholaminergic stress, i.e., the fight-or-flight response. (It should be noted that since the RyR2-S2808A mutation 

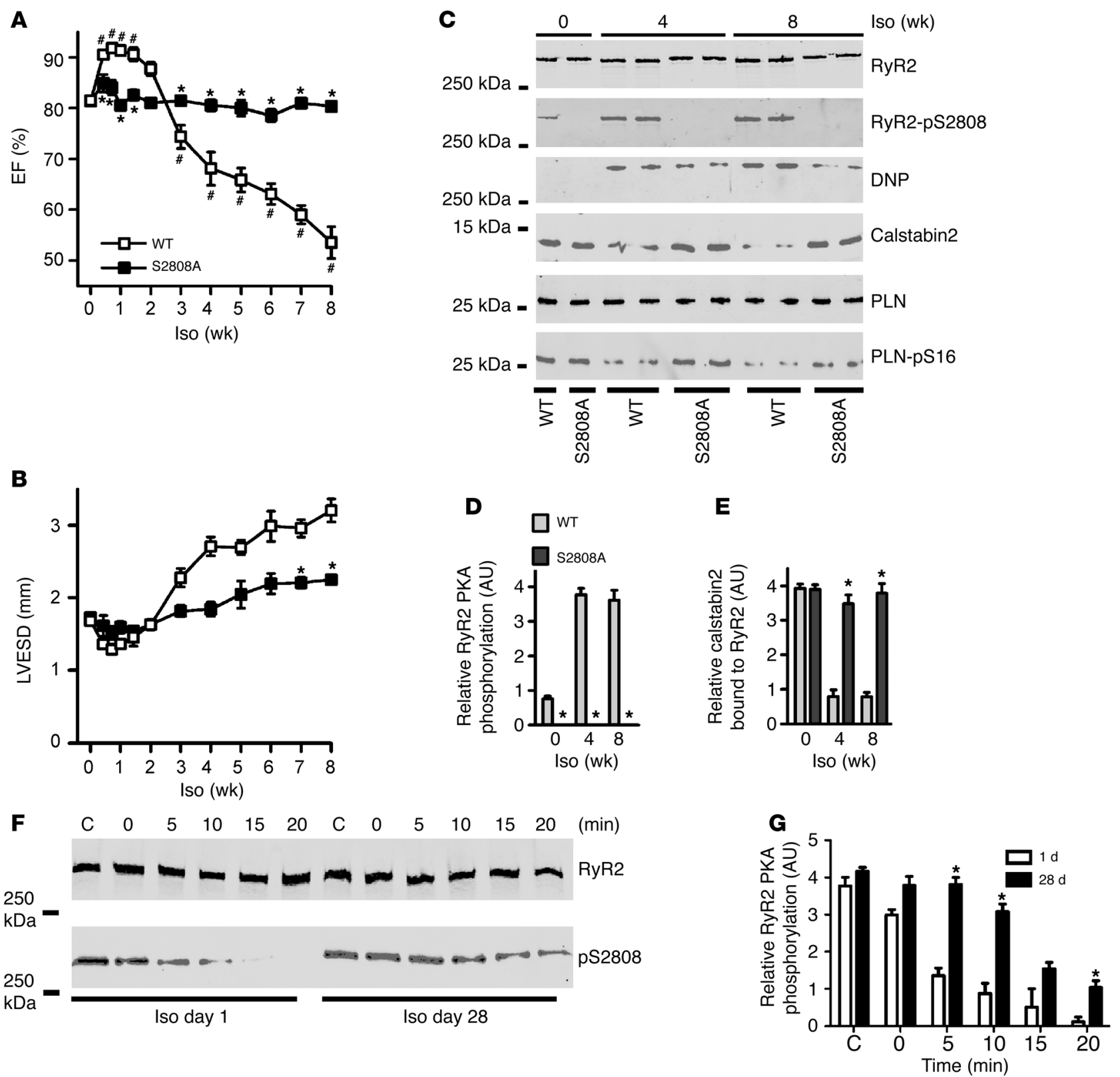

H WT + Iso (free cis $\mathrm{Ca}^{2+}=150 \mathrm{nM}$ ) Po 0.027 , To $1.9 \mathrm{~ms}$, Tc $27 \mathrm{~ms}$

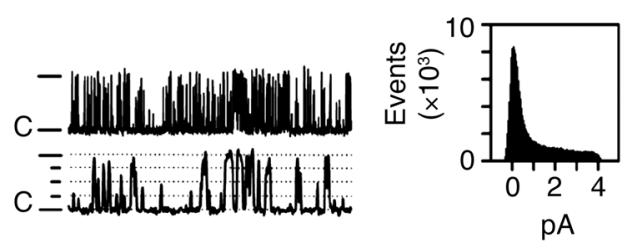

I $\quad \mathrm{S}_{2808 \mathrm{~A}^{+/+}}+$Iso (free cis $\mathrm{Ca}^{2+}=150 \mathrm{nM}$ ) Po 0.02, To $3.9 \mathrm{~ms}$, Tc $1275 \mathrm{~ms}$

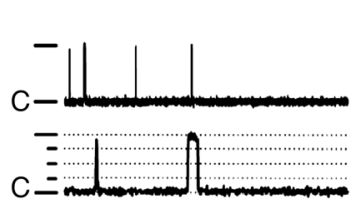

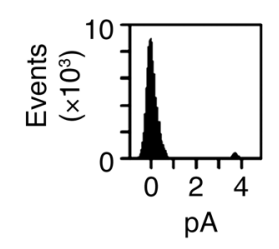

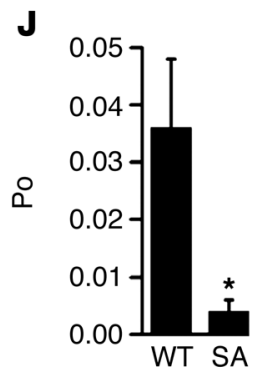




\section{Figure 7}

Chronic $\beta$-adrenergic stimulation causes cardiac dysfunction and remodeling of the RyR2 channel complex. (A) Echocardiography of left ventricular EF (A) and LVESD (B) in WT mice and RyR2-S2808 $\mathrm{A}^{+/+}$ mice during chronic Iso treatment $(n=6$ in both groups; mean \pm SEM; ${ }^{*} P<0.05$ versus WT; $\# P<0.05$ versus WT baseline). (C) Equivalent amounts of RyR2 were immunoprecipitated with RyR2-specific antibody followed by immunoblotting for relative PKA phosphorylation of RyR2 at Ser2808, oxidation (DNP), and of calstabin2 bound to RyR2. Immunoblotting of PLN- and PKA-phosphorylated PLN was performed on whole heart lysates from WT and RyR2-S2808A $\mathrm{A}^{+/+}$mice. (D and E) Quantification summaries. Mice were continuously treated with Iso for 56 days at a dose of $30 \mathrm{mg} / \mathrm{kg} / \mathrm{d}$ (WT, $n=3$; RyR2-S2808A ${ }^{+/+}, n=3$; mean $\pm \mathrm{SD}$; $\left.{ }^{*} P<0.05\right)$. (F) Aliquots of cardiac lysates from WT mice treated with Iso for 1 or 28 days were incubated at $37^{\circ} \mathrm{C}$ before the addition of phosphatase inhibitors at the indicated times (top) to stop the RyR2 dephosphorylation reaction. (G) Quantification of RyR2 PKA phosphorylation from $\mathbf{F}\left({ }^{\star} P<0.05\right)$. (H) Cardiac RyR2 single-channel activity measured from microsomes from Iso-treated WT and (I) RyR2-

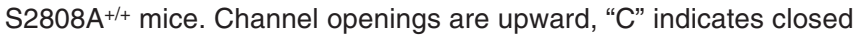
state of the channel, and dotted lines indicate levels of partial openings or subconductance states. Top dash indicates the fully open $4 \mathrm{pA}$ level. The top tracings are condensed time scale (5s) and the bottom tracings are expanded time scale $(500 \mathrm{~ms})$. Amplitude histograms are shown for each channel. To, average open time; Tc, average closed time. (J) Summary of WT ( $n=6$ channels from 3 mice) and RyR2$\mathrm{S}^{2808 \mathrm{~A}^{+/+}}(n=8$ channels from 3 mice $)$ Po. ${ }^{\star} P<0.05$.

is expressed in multiple tissues, including regions of the brain in the knockin mice, we cannot exclude the possibility that extracardiac factors contributed to the impaired exercise capacity).

The considerable blunting of the contractile response to $\beta$-adrenergic activation in the RyR2-S2808 $\mathrm{A}^{+/+}$mice is a combined effect of the reduced inotropic and chronotropic responses. In fact, when we controlled for heart rate, the differences in the contractile response to Iso between the RyR2-S2808 ${ }^{+/+}$and WT mice were reduced but remained significant. In other words, there are 2 components that contribute to the blunted contractility response to Iso in the RyR2-S2808 $\mathrm{A}^{+/+}$mice: (a) reduced inotropic response caused by a decrease in the $\mathrm{Ca}^{2+}$ transient and (b) reduced chronotropic response caused by a decreased rate of SANC depolarization; both of these components are due to the inability of PKA to phosphorylate RyR2. Thus, our data show that PKA phosphorylation of RyR2 at Ser2808 is an essential component of catecholamine-induced enhancement of cardiac contractility, in addition to the roles of enhanced $\mathrm{I}_{\mathrm{Ca}, \mathrm{L}}$ and $\mathrm{SR} \mathrm{Ca}^{2+}$ uptake.

The observation that, compared with WT mice, the Iso-induced enhancement of $\mathrm{I}_{\mathrm{Ca}, \mathrm{L}}$ and SERCA2a activity were preserved in RyR2-S2808A ${ }^{+/+}$mice but the Iso-induced increase in the $\mathrm{Ca}^{2+}$ transient amplitude was reduced indicates that impaired catecholamine-induced stimulation of SR $\mathrm{Ca}^{2+}$ release contributes to the blunted contractile response, due to inability of PKA to phosphorylate RyR2 channels. The normal catecholamine-induced increase in contractility requires enhancement of 3 key components of the $\mathrm{Ca}^{2+}$ handling machinery: (a) the trigger $\mathrm{I}_{\mathrm{Ca}, \mathrm{L}} ;(\mathrm{b})$ the uptake (via SERCA2a); and (c) the SR Ca ${ }^{2+}$ release (via RyR2). In the present study, we show that if Iso-induced enhancement of $\mathrm{SR} \mathrm{Ca}^{2+}$ release (via PKA phosphorylation of RyR2) is reduced (as it is in the RyR2$\mathrm{S}_{2808 \mathrm{~A}^{+/+}}$mice, e.g., Figure 5, A and B), then EC coupling gain is reduced (i.e., the increase in $\mathrm{SR} \mathrm{Ca}^{2+}$ release for a given increase in $\mathrm{I}_{\mathrm{Ca}, \mathrm{L}}$ is reduced). Thus, the effect of Iso on WT cardiomyocytes is to increase $\mathrm{SR} \mathrm{Ca}^{2+}$ release (i.e., increased contractility) but to maintain EC coupling gain (no increase or decrease), because $\mathrm{Ca}^{2+}$ influx, uptake, and release are all increased by Iso equivalently. To our knowledge, the new, important contribution of the present study is that PKA phosphorylation of RyR2 contributes to the stress-induced increase in contractility.

Our data would appear to contradict the proposal by Eisner and colleagues that simply increasing the Po of the RyR produces only a transient increase of systolic $\left[\mathrm{Ca}^{2+}\right]_{i}$ that cannot account for sustained increases in contractility. In one experiment in which they added low concentrations of caffeine to cardiomyocytes, they reported an immediate increase in the amplitude of the systolic $\mathrm{Ca}^{2+}$ transient that resulted in increased $\mathrm{Ca}^{2+}$ efflux from the cell, net loss of $\mathrm{Ca}^{2+}$ from the $\mathrm{SR}$, and the return of systolic $\mathrm{Ca}^{2+}$ to basal levels over just a few beats (20). On the basis of this experiment, they and others have argued that RyR phosphorylation cannot cause a steady-state increase in contractility. However, the caffeine experiment of Eisner et al. was designed such that only 1 out of the 3 important components of the stress-induced increase in contractility was activated, namely the RyR2 channel (by caffeine). In the present study, we show that when the activity of L-type channel and SERCA2a increase (as occurs normally in response to stress), but RyR2 activity does not increase (because it cannot be PKA phosphorylated), then the result is a sustained reduction of contractility compared with that of WT mice. The experiment by Eisner et al. shows what happens if only 1 out of the 3 components (RyR2) is activated: there is no sustained enhancement of contractility. However, the results from their cellular experiments, in which RyR2 is artificially activated in absence of L-type and SERCA2a activation, do not adequately address the actual role of RyR2 activation in vivo during stress. On the basis of our in vivo, ex vivo, cellular, and single-channel studies, we conclude that PKA phosphorylation of RyR2 plays an essential role in the stressinduced enhancement of contractility.

Since more $\mathrm{Ca}^{2+}$ is entering the cell during stress and more $\mathrm{Ca}^{2+}$ is being pumped into the $\mathrm{SR}, \mathrm{SR} \mathrm{\textrm {Ca } ^ { 2 + }}$ release also has to increase to enhance contractility. We have previously shown that PKA phosphorylation of RyR2 increases the Po of the channel (9) and that a phosphomimetic PKA-phosphorylated channel (RyR2-S2808D) has increased sensitivity to $\mathrm{Ca}^{2+}$-dependent activation (10). Thus, PKA phosphorylation of RyR2 increases the sensitivity of the channel to activating $\mathrm{Ca}^{2+}$ entering via the L-type channel and enables the channel to release more $\mathrm{Ca}^{2+}$, thereby contributing to increased contractility. Additional mechanisms, including synchronization of RyR2 channels (17), may also play a role.

There is controversy as to whether or not PKA phosphorylation of RyR 2 can disrupt the interaction between calstabin 2 and RyR2 $(9,42)$. We now demonstrate that oxidation of RyR2 enhances the ability of PKA phosphorylation of the channel to dissociate calstabin2 from the RyR2 macromolecular complex. In contrast, CaMKII phosphorylation of RyR2, in combination with oxidation, did not disrupt the interaction between RyR2 and calstabin2. Since the oxidation state of RyR2 has not been regularly assessed, this likely accounts for variable results reported for the effect of PKA phosphorylation of RyR2 and its ability to dissociate calstabin2 from the channel. In the present study, we showed that acute PKA phosphorylation of RyR2 during the fight-or-flight stress contributes to enhanced cardiac contractility. In contrast, chronic RyR2 PKA hyperphosphorylation (for example, during HF when RyR2 channels are also oxidized) causes calstabin2 depletion from the channel complex, which results in a pathological SR $\mathrm{Ca}^{2+}$ leak, HF 
progression, and arrhythmias. Chronic RyR2 PKA hyperphosphorylation and the resultant chronic depletion of calstabin2 from the channel complex is not a normal physiological response and is not required for enhanced contractility during fight or flight.

MacDonnell et al. (12) previously reported that their RyR2$\mathrm{S} 2808 \mathrm{~A}^{+/+}$mice have normal chronotropic and inotropic responses to Iso. However, MacDonnell et al. only examined a single Iso dose ( $2 \mathrm{mg} / \mathrm{kg}$ i.p.). We now show that this higher Iso dose obscures the inotropic and chronotropic defects in the RyR2-S2808 $\mathrm{A}^{+/+}$mice. We also found that the lower Iso dose induced specific phosphorylation of Ser2808, whereas the higher Iso dose caused additional phosphorylation at Ser2814, the CaMKIId phosphorylation site on RyR2 $(10,29)$. While this observation supports reports by other groups that Iso can induce CaMKIId activation (43), it appears that this effect is only seen at a very high dose of Iso and suggests that CaMKIID-mediated phosphorylation of RyR2 is responsible for the inotropic and chronotropic responses to such a high dose of Iso in the RyR2-S2808A $\mathrm{A}^{+/+}$mice, because these responses are not observed at lower doses of Iso.

In ex vivo studies, MacDonnell et al. continuously paced WT and RyR2-S2808A $\mathrm{A}^{+/+}$hearts at $460 \mathrm{bpm}$ before and during Iso infusion (12). Since under non-paced conditions Iso causes ex vivo WT hearts to beat at a rate faster than $460 \mathrm{bpm}$, we performed our experiments on non-paced hearts in order to avoid placing artificial restrictions on the $\beta$-adrenergic response. Our results demonstrate a significant reduction in Iso-induced contractility in RyR2S2808A ${ }^{+/+}$hearts under these conditions that was not observed by MacDonnell et al. (12).

Benkusky et al. (15) previously reported no differences in $\mathrm{Ca}^{2+}$ transient amplitude in the absence or presence of $1 \mu \mathrm{M}$ Iso between WT and RyR2-S2808A ${ }^{+/+}$ventricular cardiomyocytes when the cells were subjected to low stimulation rates (e.g., $1 \mathrm{~Hz}$ ). However, in agreement with our studies, these authors did report a significant reduction in $\mathrm{SR} \mathrm{Ca}^{2+}$ release in the $\mathrm{RyR} 2-\mathrm{S} 2808 \mathrm{~A}^{+/+}$ ventricular cardiomyocytes paced at $3 \mathrm{~Hz}$, compared with that in WT cardiomyocytes.

Having demonstrated the physiologic role of acute PKA phosphorylation of RyR2 in the cardiac fight-or-flight response, we investigated the effects of chronic PKA hyperphosphorylation of RyR2 as occurs in patients with $\operatorname{HF}(9,34)$. Patients with HF have a chronic hyperadrenergic state that has been linked to adverse clinical outcomes (44). We have previously shown that in HF, chronic PKA hyperphosphorylation of RyR2 induces remodeling of the channel macromolecular complex, which would result in SR $\mathrm{Ca}^{2+}$ leak and depletion of SR $\mathrm{Ca}^{2+}$ stores (9). These earlier findings are supported by the observation that the RyR2-S2808A $\mathrm{A}^{+/+}$mice are protected against HF progression manifested as a preservation of cardiac function after MI (21). During the first 2 weeks of chronic Iso treatment, the WT mice exhibited enhanced cardiac function compared with baseline. However, after 2 weeks there was a progressive decline in cardiac function in the WT mice, which did not occur in the RyR2-S2808A $\mathrm{A}^{+/+}$mice. The cardiac dysfunction in the WT mice was associated with chronic PKA hyperphosphorylation and oxidation of RyR2, remodeling of the channel complex, and leaky channels with increased $\mathrm{Po}$ at diastolic activating $\left[\mathrm{Ca}^{2+}\right]$. However, both RyR2-S2808A $\mathrm{A}^{+/}$and WT mice showed significant left ventricular hypertrophy, although the hypertrophy was significantly less in the RyR2-S2808A $\mathrm{A}^{+/+}$mice (Supplemental Table 5), and there were no differences in myocyte apoptosis after 8 weeks of chronic Iso treatment (45). Thus, our data suggest that the RyR2-
S2808A mutation preserves cardiac function but only partially prevents the hypertrophic response to Iso. Moreover, in a companion paper (46), we show that mimicking one effect of chronic Iso infusion, chronic PKA phosphorylation of RyR2, with RyR2S2808D mutant mice results in an SR $\mathrm{Ca}^{2+}$ leak and a progressive cardiomyopathy. Inhibiting the diastolic SR $\mathrm{Ca}^{2+}$ leak with S107 prevents the cardiomyopathy in RyR2-S2808D mice but does not completely reduce the hypertrophy. Taken together, these data show that preventing chronic PKA hyperphosphorylation of RyR2 in the RyR2-S2808A mice protects against some, but not all, of the toxic effects of chronic Iso infusion.

The stoichiometry of phosphorylation of RyR2-S2808 is such that at rest less than 1 out of the 4 sites is PKA phosphorylated. During acute $\beta$-adrenergic activation, 3-4 PKA of the 4 PKA sites (i.e., the 4 RyR2-Ser2808 sites in each homotetrameric channel) are transiently phosphorylated, resulting in a leftward shift of the sensitivity to activating (cytosolic) $\mathrm{Ca}^{2+}(9)$. This is part of the normal physiological response to stress (fight-or-flight). In the RyR2S2808A $\mathrm{A}^{+/+}$mice, this physiological response to stress is blunted (reduced inotropic and chronotropic responses to Iso).

In $\mathrm{HF}$, or during chronic Iso treatment, 3-4 of the 4 sites on each channel are also PKA phosphorylated; however, the phosphorylation is chronic as opposed to transient (this is PKA hyperphosphorylation). Moreover, in addition to the chronic PKA hyperphosphorylation of RyR2, prolonged adrenergic stimulation (as occurs during HF or chronic Iso administration) is associated with remodeling of the RyR2 channel macromolecular complex (including oxidation, depletion of calstabin2, decreased phosphatase and phosphodiesterase levels, and reduced activity in the complex) $(9,47)$. The combined effects of chronic PKA hyperphosphorylation and RyR2 complex remodeling are associated with instability of the closed state of the channel, leading to pathologic diastolic SR calcium leak, which promotes HF progression (9). Indeed, the RyR2-S2808A ${ }^{+/+}$mice are protected against post-MI HF progression (21) and chronic Iso-induced cardiac dysfunction.

To further explore the mechanisms underlying the cardiac dysfunction observed in the WT mice chronically treated with Iso as well as the relationship between phosphorylation and oxidation of RyR2 and calstabin2 depletion, we developed what we believe to be a novel transgenic mouse with aspartic acid in place of Ser2808 on RyR2 (RyR2-S2808D), which mimics chronically hyperphosphorylated RyR2. This enables us to isolate the specific contribution of chronic hyperphosphorylation of RyR2-Ser2808 in the development of HF. The results from this study are presented in the companion paper (46) accompanying this manuscript.

In summary, we have found that mice harboring RyR2 that cannot be PKA phosphorylated have blunted chronotropic and inotropic responses to catecholaminergic activation and impaired exercise capacity and are protected from the detrimental effects of chronic $\beta$-adrenergic activation. Thus, the present study elucidates the role of PKA phosphorylation of RyR2 in the fight-or-flight response and in the progressive decline of cardiac function in HF.

\section{Methods}

RyR2-S2808A ${ }^{+/+}$mice. RyR2-S2808A ${ }^{+/+}$mutant mice were generated using homologous recombination as previously described and were backcrossed more than 6 generations into the C57BL/ 6 background (21). RyR2 channels isolated from the RyR2-S2808A ${ }^{+/+}$mice were unable to be PKA phosphorylated, as evidenced by ${ }^{[32]}$ P-ATP incorporation, even after maximal dephosphorylation with phosphatases as previously reported (21). 
Hearts from RyR2-S2808A $\mathrm{A}^{+/+}$mice were structurally normal, based on histological sections (21), and had normal cardiac function at rest, as assessed by cardiac echocardiography and intracardiac left ventricular catheterization measurements (Supplemental Table 2). All experiments with animals were approved by Columbia University's Institutional Animal Care and Use Committee. In all cases, individuals conducting all experiments were blinded to the genotype and treatment status of the animals.

Hemodynamic analyses. Left ventricular catheterization and cardiac echocardiography measurements were performed as previously described $(21,29)$. Inotropic drug application was administered via infusion into the jugular vein through a custom-made cannula (e.g., Iso $100 \mathrm{ng} \mathrm{kg}^{-1} \mathrm{~min}^{-1}$ i.v.). The end-systolic pressure-volume relationship, $E_{\mathrm{es}}$, heart rate, and additional parameters were determined during inferior vena cava occlusion by linear regression analysis from at least 10 consecutive cardiac cycles, recorded at baseline or during the maximal response to an inotropic intervention (Iso, db-cAMP, Bay K 8644, ouabain, $\mathrm{Ca}^{2+}$ [all from Sigma-Aldrich]), as indicated in the insets of Figure 2, A-C, by automated software analysis (IOX, Emkatech). Echocardiography (Vevo 770 High-Resolution Mouse In Vivo Imaging System, Visualsonics) was performed with a 30-MHz mouse scan head.

Ex vivo contractility. Hearts from WT and RyR2-S2808A $\mathrm{A}^{+/+}$mice were surgically removed and cannulated. The hearts were then retrogradely perfused with a modified Krebs solution $\left(118.5 \mathrm{mM} \mathrm{NaCl}, 25 \mathrm{mM} \mathrm{NaHCO}_{3}\right.$, $4.7 \mathrm{mM} \mathrm{KCl}, 1.2 \mathrm{mM} \mathrm{MgSO}_{4}, 1.2 \mathrm{mM} \mathrm{KH}_{2} \mathrm{PO}_{4}, 11 \mathrm{mM}$ glucose, $1.8 \mathrm{mM}$ $\mathrm{Ca}^{2+}$ ) on a Langendorff system. Left ventricular pressure was measured using a balloon catheter connected to an APT-300 pressure transducer (ADInstruments). The pressure transducer was connected to a PowerLab digitizer (ADInstruments). Hearts that failed to meet the following criteria were excluded from the study: baseline developed pressure above $50 \mathrm{mmHg}$ and maximum heart rates after Iso below $610 \mathrm{bpm}$.

Immunoprecipitation and immunoblot analysis. Cardiac homogenates $(100 \mu \mathrm{g})$ were used to immunoprecipitate RyR2 channels with anti-RyR antibody (48). RyR2 was immunoprecipitated by incubating $100 \mu \mathrm{g}$ cardiac homogenate with anti-RyR antibody $(2 \mu \mathrm{l} 5029 \mathrm{Ab})$ in $0.5 \mathrm{ml}$ of a modified RIPA buffer $(50 \mathrm{mM}$ Tris-HCl, pH 7.4, 0.9\% NaCl, $5.0 \mathrm{mM} \mathrm{NaF}, 1.0 \mathrm{mM} \mathrm{Na}_{3} \mathrm{VO}_{4}, 0.5 \%$ Triton-X100, and protease inhibitors) for 2 hours at $4{ }^{\circ} \mathrm{C}$. For oxidation experiments, $1 \mathrm{mM}$ hydrogen peroxide was incubated with $200 \mu \mathrm{g}$ CSR for 30 minutes at room temperature. PKA and CaMKII phosphorylation of RyR2 were performed as previously described (29). The samples were then incubated with protein A sepharose beads (Amersham Pharmacia Biotech) at $4^{\circ} \mathrm{C}$ for 1 hour, after which the beads were washed 5 times with $1.0 \mathrm{ml}$ RIPA. Samples were heated to $95^{\circ} \mathrm{C}$ and size fractionated by PAGE (6\% for RyR, $15 \%$ for calstabin). Proteins were transferred to nitrocellulose membranes and immunoblots were developed using the following antibodies: anti-calstabin $(1: 1,000)(41)$, antiRyR (5029; 1:3,000) (48), anti-phospho-RyR2-pSer 2808 (1:5,000) (10), or antiphospho-RyR2-pSer $2814(1: 5,000)(10)$. To assess ROS-mediated formation of carbonyls on RyR2, the immunoprecipitate was treated with 2, 4-dinitrophenyl hydrazine, and the derivatized carbonyls were detected using an OxyBlot Protein Oxidation Detection Kit (catalog S7150, Chemicon International Inc.). To determine the amount of total and phosphorylated PLN in heart homogenates, $10 \mu \mathrm{g}$ protein was size fractionated on 15\% SDS-PAGE and immunoblots were developed using anti-PLN for PLN (1:1,000, dilution in 5\% milk TBS-T, Research Diagnostics), a PKA phospho-specific PLN antibody (1:1,000, PS-16 Ab, Research Diagnostics). All immunoblots were developed using the Odyssey system (LI-COR Inc.), using IR-labeled anti-mouse and anti-rabbit IgG (1:10,000 dilution) secondary antibodies.

Single-channel recordings. Vesicles containing native or recombinant RyR2 were fused to planar lipid bilayers in $100-\mu \mathrm{m}$ holes in polystyrene cups separating 2 chambers. The trans chamber $(1.0 \mathrm{ml})$, representing the intra-SR compartment, was connected to the headstage input of a bilayer voltageclamp amplifier (Warner Instruments). The cis chamber $(1.0 \mathrm{ml})$, represent- ing the cytoplasmic compartment, was held at virtual ground. Symmetrical solutions used are as follows: trans, $250 \mathrm{mM}$ HEPES, $53 \mathrm{mM} \mathrm{Ca}(\mathrm{OH})_{2}, \mathrm{pH}$ 7.35; cis, $250 \mathrm{mM}$ HEPES, $125 \mathrm{mM}$ Tris, $1.0 \mathrm{mM}$ EGTA, $0.5 \mathrm{mM} \mathrm{CaCl}_{2}$, $\mathrm{pH}$ 7.35. At the conclusion of each experiment, $5 \mu \mathrm{M}$ ryanodine or $20 \mu \mathrm{M}$ ruthenium red was applied to confirm RyR2 channel identity.

Cardiomyocyte fluorescence and fractional shortening. Ventricular myocytes were isolated according to a modified version of the Alliance for Cellular Signaling protocol PP00000125. Briefly, the cells were digested with Liberase Blendzyme 1 (Roche) and then the $\mathrm{Ca}^{2+}$ concentration was slowly brought up to $1.8 \mathrm{mM}$. The cells were then resuspended in a modified Tyrode solution: $137 \mathrm{mM} \mathrm{NaCl}, 5 \mathrm{mM} \mathrm{KCl}, 1 \mathrm{mM} \mathrm{MgCl} 2,1.8 \mathrm{mM} \mathrm{CaCl}_{2}, 10 \mathrm{mM}$ glucose, $10 \mathrm{mM}$ HEPES. The $\mathrm{pH}$ was adjusted to 7.4 with $\mathrm{NaOH}$. Fractional shortening measurements were taken using a Nikon Diaphot microscope connected to a video edge detection system (Crescent Electronics), driven by a PC running FeliX32 (Photon Technology International). $\mathrm{Ca}^{2+}$ fluorescence measurements were taken by first loading the cells for 20 minutes with $3 \mu \mathrm{M}$ Fura 2-am (Molecular Probes) and allowing them to rest for at least 10 minutes prior to the experiment. Excitation light was produced using a DeltaramV High Speed Random Access Monochromator (PTI). Fluorescence recordings were made using an 814 Photomultiplier Detection System (PTI), connected to a PC running FeliX32 (PTI). Cells were paced at $3.0 \mathrm{~Hz}$ for at least 1 minute before a baseline measurement was made. The cells were then perfused with Tyrode containing $100 \mathrm{nM}$ Iso.

Exercise studies. Mice were placed in a round pool (diameter $122 \mathrm{~cm}$ ) filled with water $\left(21^{\circ} \mathrm{C} \pm 1^{\circ} \mathrm{C}\right)$, which was rendered opaque by the addition of nontoxic white paint (Discount School Supply). Swimming velocity and distance were measured using a Sony Digital camera, connected to a PC running SMART software version 2.5 (San Diego Instruments). Mice used in this study were untrained (i.e., they had never been previously placed in water), and the study was performed by an observer blinded to the genotype of the mice.

Statistics. Data are reported as mean \pm SEM unless indicated otherwise. Concentration-effect relationships were analyzed by 2 -way repeated-measures ANOVA, with interaction terms between Iso dose and genotype. A 2 -tailed Student's $t$ test was used for comparison among groups. $P<0.05$ was accepted as statistically significant.

\section{Acknowledgments}

We wish to acknowledge Anetta Wronska, Bi-Xing Chen, and Peter Murphy for their technical assistance and Andrew Bellinger for helpful discussions. This work was supported by NHLBI grants HL061503 and HL056180.

Received for publication June 21, 2010, and accepted in revised form September 29, 2010.

Address correspondence to: Andrew R. Marks, Department of Physiology and Cellular Biophysics, Russ Berrie Medical Sciences Pavilion, Room 520, 1150, St. Nicholas Ave., New York, New York 10032, USA. Phone: 212.851.5337; Fax: 212.851.5346; E-mail: arm42@columbia.edu.

Stephan E. Lehnart's present address is: Abteilung Kardiologie und Pneumologie, Georg-August-Universität, Göttingen, Germany.

Nicolas Lindegger's present address is: Actelion Pharmaceuticals, Basel, Switzerland.

Marco Mongillo's present address is: Università di Padova, Padova, Italy. 
1. Vatner SF. Sympathetic mechanisms regulating myocardial contractility in concious animals. In Fozzard HA, Haber E, eds. The Heart and Cardiovascular System. New York, New York, USA: Raven Press, Ltd; 1992:1709-1728.

2. Rohrer DK. Physiological consequences of beta-adrenergic receptor disruption. J Mol Med. 1998;76(11):764-772.

3. Bers DM. Cardiac excitation-contraction coupling. Nature. 2002;415(6868):198-205.

4. Fabiato A. Simulated calcium current can both cause calcium loading in and trigger calcium release from the sarcoplasmic reticulum of a skinned canine cardiac Purkinje cell. J Gen Physiol. 1985;85(2):291-320.

5. Cannell MB, Berlin JR, Lederer WJ. Effect of membrane potential changes on the calcium transient in single rat cardiac muscle cells. Science. 1987;238(4832):1419-1423

6. Nabauer M, Callewaert G, Cleemann L, Morad M. Regulation of calcium release is gated by calcium current, not gating charge, in cardiac myocytes. Science. 1989;244(4906):800-803.

7. De Jongh KS, Murphy BJ, Colvin AA, Hell JW, Takahashi M, Catterall WA. Specific phosphorylation of a site in the full-length form of the alpha 1 subunit of the cardiac L-type calcium channel by adenosine $3^{\prime}, 5^{\prime}$-cyclic monophosphate-dependent protein kinase. Biochemistry. 1996;35(32):10392-10402.

8. Chu G, Lester JW, Young KB, Luo W, Zhai J, Kranias EG. A single site (Ser16) phosphorylation in phospholamban is sufficient in mediating its maximal cardiac responses to beta-agonists. J Biol Chem. 2000;275(49):38938-38943.

9. Marx SO, et al. PKA phosphorylation dissociates FKBP12.6 from the calcium release channel (ryanodine receptor): defective regulation in failing hearts. Cell. 2000;101(4):365-376.

10. Wehrens XH, Lehnart SE, Reiken SR, Marks AR $\mathrm{Ca} 2+/$ calmodulin-dependent protein kinase II phosphorylation regulates the cardiac ryanodine receptor. Circ Res. 2004;94(6):e61-e70.

11. Ginsburg KS, Bers DM. Modulation of excitationcontraction coupling by isoproterenol in cardiomyocytes with controlled SR Ca2+ load and $\mathrm{Ca} 2+$ current trigger. J Physiol. 2004;556(pt 2):463-480.

12. MacDonnell SM, et al. Adrenergic regulation of cardiac contractility does not involve phosphorylation of the cardiac ryanodine receptor at serine 2808. Circ Res. 2008;102(8):e65-72.

13. Eisner DA, Kashimura T, O'Neill SC, Venetucci LA, Trafford AW. What role does modulation of the ryanodine receptor play in cardiac inotropy and arrhythmogenesis? J Mol Cell Cardiol. 2009;46(4):474-481.

14. Lehnart S, Marks AR. Regulation of ryanodine receptors in the heart. Circ Res. 2007;101(8):746-749.

15. Benkusky NA, et al. Intact beta-adrenergic response and unmodified progression toward heart failure in mice with genetic ablation of a major protein kinase A phosphorylation site in the cardiac ryanodine receptor. Circ Res. 2007;101(8):819-829.
16. Zhou P, et al. Beta-adrenergic signaling accelerates and synchronizes cardiac ryanodine receptor response to a single L-type Ca2+ channel. Proc Natl Acad Sci U S A. 2009;106(42):18028-18033.

17. Song LS, Wang SQ, Xiao RP, Spurgeon H, Lakatta EG, Cheng H. beta-Adrenergic stimulation synchronizes intracellular $\mathrm{Ca}(2+)$ release during excitation-contraction coupling in cardiac myocytes. Circ Res. 2001;88(8):794-801.

18. Ogrodnik J, Niggli E. Increased $\mathrm{Ca}(2+)$ leak and spatiotemporal coherence of $\mathrm{Ca}(2+)$ release in cardiomyocytes during beta-adrenergic stimulation. JPhysiol. 2010;588(pt 1):225-242.

19. Lindegger N, Niggli E. Paradoxical SR Ca2 + release in guinea-pig cardiac myocytes after beta-adrenergic stimulation revealed by two-photon photolysis of caged Ca2+. J Physiol. 2005;565(pt 3):801-813.

20. Trafford AW, Diaz ME, Sibbring GC, Eisner DA. Modulation of CICR has no maintained effect on systolic $\mathrm{Ca} 2+$ : simultaneous measurements of sarcoplasmic reticulum and sarcolemmal $\mathrm{Ca} 2+$ fluxes in rat ventricular myocytes. J Physiol. 2000;522 pt 2:259-270.

21. Wehrens XH, Lehnart SE, Reiken S, Vest JA, Wronska A, Marks AR. Ryanodine receptor/calcium release channel PKA phosphorylation: a critical mediator of heart failure progression. Proc Natl Acad Sci U S A. 2006;103(3):511-518.

22. DiFrancesco D. The contribution of the 'pacemaker' current (if) to generation of spontaneous activity in rabbit sino-atrial node myocytes. J Physiol. 1991;434:23-40.

23. Irisawa H, Brown HF, Giles W. Cardiac pacemaking in the sinoatrial node. Physiol Rev. 1993; 73(1):197-227.

24. DiFrancesco D, Tortora P. Direct activation of cardiac pacemaker channels by intracellular cyclic AMP. Nature. 1991;351(6322):145-147.

25. DiFrancesco D, Ducouret P, Robinson RB. Muscarinic modulation of cardiac rate at low acetylcholine concentrations. Science. 1989;243(4891):669-671.

26. Ju YK, Allen DG. Intracellular calcium and $\mathrm{Na}+$ $\mathrm{Ca} 2+$ exchange current in isolated toad pacemaker cells. J Physiol 1998;508(pt 1):153-166.

27. Maltsev VA, Lakatta EG. Normal heart rhythm is initiated and regulated by an intracellular calcium clock within pacemaker cells. Heart Lung Circ. 2007;16(5):335-348.

28. Vinogradova TM, Bogdanov KY, Lakatta EG. betaAdrenergic stimulation modulates ryanodine receptor $\mathrm{Ca}(2+)$ release during diastolic depolarization to accelerate pacemaker activity in rabbit sinoatrial nodal cells. Circ Res. 2002;90(1):73-79.

29. Kushnir A, Shan J, Betzenhauser MJ, Reiken S, Marks AR. Role of CaMKIIdelta phosphorylation of the cardiac ryanodine receptor in the force frequency relationship and heart failure. Proc Natl Acad Sci U S A. 2010;107(22):10274-10279.

30. Luo W, Chu G, Sato Y, Zhou Z, Kadambi VJ, Kranias EG. Transgenic approaches to define the functional role of dual site phospholamban phosphorylation. J Biol Chem. 1998;273(8):4734-4739.

31. Xin HB, et al. Oestrogen protects FKBP12.6 null mice from cardiac hypertrophy. Nature. 2002; 416(6878):334-338.

32. Bowditch HP. Über die Eigentümlichkeiten der Reizbarkeit welche die Muskelfasern des Herzens zeigen. Ber Verh Saechs Akad Wiss,. 1871;23:652-689.

33. Chidsey CA, Harrison DC, Braunwald E. Augmentation of the plasma nor-epinephrine response to exercise in patients with congestive heart failure. N Engl J Med. 1962;267:650-654.

34. Reiken $S$, et al. Beta-blockers restore calcium release channel function and improve cardiac muscle performance in human heart failure. Circulation. 2003;107(19):2459-2466.

35. Packer M, et al. The effect of carvedilol on morbidity and mortality in patients with chronic heart failure. U.S. Carvedilol Heart Failure Study Group. N Engl J Med. 1996;334(21):1349-1355.

36. Balakumar P, Singh AP, Singh M. Rodent models of heart failure. J Pharmacol Toxicol Methods. 2007; 56(1):1-10.

37. Galindo CL, et al. Transcriptional profile of isoproterenol-induced cardiomyopathy and comparison to exercise-induced cardiac hypertrophy and human cardiac failure. BMC Physiol. 2009;9:23.

38. Cachelin AB, de Peyer JE, Kokubun S, Reuter H. Ca2+ channel modulation by 8-bromocyclic AMP in cultured heart cells. Nature. 1983;304(5925):462-464.

39. Bers DM. Calcium cycling and signaling in cardiac myocytes. Annu Rev Physiol. 2008;70:23-49.

40. Valdivia HH, Kaplan JH, Ellis-Davies GC, Lederer WJ. Rapid adaptation of cardiac ryanodine receptors: modulation by $\mathrm{Mg} 2+$ and phosphorylation. Science. 1995;267(5206):1997-2000.

41. Wehrens XH, et al. FKBP12.6 deficiency and defective calcium release channel (ryanodine receptor) function linked to exercise-induced sudden cardiac death. Cell. 2003;113(7):829-840.

42. Xiao B, Sutherland C, Walsh MP, Chen SR. Protein kinase A phosphorylation at serine-2808 of the cardiac Ca2+-release channel (ryanodine receptor) does not dissociate 12.6-kDa FK506-binding protein (FKBP12.6). Circ Res. 2004;94(4):487-495.

43. Ferrero $P$, et al. Ca2+/calmodulin kinase II increases ryanodine binding and $\mathrm{Ca} 2+$-induced sarcoplasmic reticulum $\mathrm{Ca} 2+$ release kinetics during betaadrenergic stimulation. J Mol Cell Cardiol. 2007; 43(3):281-291.

44. Cohn JN, et al. Plasma norepinephrine as a guide to prognosis in patients with chronic congestive heart failure. N Engl J Med. 1984;311(13):819-823.

45. Chien KR. Stress pathways and heart failure. Cell. 1999;98(5):555-558.

46. Shan J, et al. Role of chronic ryanodine receptor phosphorylation in heart failure and $\beta$-adrenergic receptor blockade in mice. J Clin Invest. 2010; 120(12):4375-4387

47. Lehnart SE, et al. Phosphodiesterase 4D deficiency in the ryanodine-receptor complex promotes heart failure and arrhythmias. Cell. 2005;123(1):25-35.

48. Jayaraman T, et al. FK506 binding protein associated with the calcium release channel (ryanodine receptor). J Biol Chem. 1992;267(14):9474-9477. 